\title{
Patterns of Consumption
}

Editor: M. Krausz (Hamburg)

Eur Addict Res 2001;7:1

\section{Editorial}

\author{
Christian Haasen, Hamburg
}

If we want to consider addiction to be a disease entity, the variety of patterns of consumption forces us to see this entity as a complex model of etiological factors. The fact that there are so many different patterns of consumption and that these vary greatly when looking at different age groups, different professional groups, social status and regional or cultural backgrounds can lead to an underestimation of social and psychological factors in this complex model of addiction. Furthermore, the historical perspective of patterns of consumption has shown important changes over time, which reflect cultural changes in societies as well as the great migratory movements and the globalisation of society as a whole. This is therefore an important aspect when studying patterns of consumption, as they always reflect important cultural norms and values of a society. If patterns of consumption follow the cultural norms and values, they are usually not labelled addictive behaviour and are not associated with secondary harmful events or diseases. But even the patterns of consumption that do not follow cultural norms and values reflect a dysfunctional pattern of coping with society and therefore always have to be studied in the social and cultural context.

The last few decades have seen a rise in addictive patterns of consumption with more than one psycho-active substance. Unfortunately this polyvalent substance use is also responsible for most emergency cases dealing with addiction, as addicts consuming only one substance usually manage to avoid harmful use. An interesting question, but very difficult to investigate, is whether this increase in polyvalent substance use is a reflection of an increasing complexity of society. Nonetheless, the combinations of substances found among polyvalent drug users more often reflect a supply than a demand perspective. The heterogeneity of substances available allows drug users to consume more according to perceived needs. The importance of peer groups in propagating the use of other substances is an important factor that needs to be considered in the research on patterns of consumption.

We are aware that a special issue of European Addiction Research on the topic of patterns of consumption cannot be expected to fully cover all aspects of such a wide field. Therefore, it seemed important to us to choose three articles that illustrate very different subpopulations. The article by Tossmann et al. supplies us with an important study of an emergent subpopulation of drug users found in and around the techno party scene. This is an important study because it presents new data on a very young group of drug users (mean age about 22 years) in seven important metropolitan cities of Europe. Considering the avant-garde character of this scene for future youth groups, it is important to develop an understanding for the pattern of consumption, described as the polydrug occasional use model. The importance of the paper is also given due to the increasing use of stimulants such as ecstasy, amphetamines and cocaine.

Livaditis et al. then draw our attention to one of the most widespread addictions - smoking. Smoking patterns have seen great changes in the last two decades: while, in countries like the USA, the overall rate has diminished due to strong antismoking campaigns, in the countries of the European Union, some have seen decreases as well while other countries have registered a significant increase. One such country is the origin of the presented study - Greece. By choosing a specific professional group, the authors were able to explore demographic and psychological patterns affecting smoking in this group. Warning evidence is presented with respect to smoking patterns among women. The higher percentage of smokers among immigrants touches upon an important aspect in addiction research, which needs to be dwelt on more in the future, that is the changing consumption patterns for migrants.

The study by Thirion et al. represents a totally different approach towards the study of consumption patterns. By analysing a large database of over 5,000 patients, an important investigation is presented for the patterns of consumption in France, despite the fact that this study is limited with respect of representativity. Nonetheless, the study has important implications in the development of national drug policy.

Considering all limitations of focussing on these three aspects, the message for future research on patterns of consumption remains clear: firstly, we need to focus on new developments of addiction with respect to new substances and new subpopulations; secondly, we have to analyse the changes in patterns of consumption of well-studied substances such as alcohol, heroin and nicotine, and thirdly, we need larger databases from which drug prevention and drug treatment programmes can be developed. We hope that the current issue will be taken by research groups as an incentive to develop research strategies for the patterns of consumption.

\begin{tabular}{ll}
\hline KARGER & ( ) 2001 S. Karger AG, Basel \\
Fax +4161306 1234 & 1022-6877/01/0071-0001\$17.50/0 \\
$\begin{array}{l}\text { E-Mail karger@karger.ch } \\
\text { www.karger.com }\end{array}$ & $\begin{array}{l}\text { Accessible online at: } \\
\text { www.karger.com/journals/ear }\end{array}$
\end{tabular}

